\title{
La (des)protección del autor extranjero de obra audiovisual
}

\author{
$* * * *$ \\ Aurelio López-Tarruella Martínez \\ Universidad de Alicante \\ aurelio.lopez@ua.es
}

Recibido: 30 de octubre de 2021

Aceptado: 16 de noviembre de 2021

\begin{abstract}
Resumen
El presente trabajo analiza las causas por las cuales el autor de obra audiovisual no recibe una remuneración equitativa cuando su obra se explota en países extranjeros. Estas razones son la diferencia entre legislaciones derivadas del principio de territorialidad y las prácticas contractuales de los productores audiovisuales. A continuación, se analizan las posibles soluciones a esta desprotección, partiendo, en primer lugar, de explicar las razones que provocan que las normativas de protección del autor en la contratación sean ineficientes cuando los contratos adquieren un carácter internacional. En segundo lugar, se aboga por la adopción de un derecho de simple remuneración por la explotación de la obra audiovisual de carácter irrenunciable y gestionado colectivamente. Por último, se explica el importante papel que las sociedades de gestión colectiva juegan para proteger al autor audiovisual extranjero en América Latina.
\end{abstract}

Palabras clave: obra audiovisual, autor extranjero, principio de territorialidad, contratos de producción audiovisual, derecho de simple remuneración, sociedades de gestión colectiva.

\section{The (lack of) protection of foreign authors of audiovisual works}

\begin{abstract}
The work analyses the reasons why authors of audiovisual works do not receive an equitable remuneration when their works are exploited in foreign countries. These reasons are the divergences among legislations deriving from the territoriality principle; and the contractual practices of audiovisual producers. The second part of the paper explains the legislative solutions to these problems. First, an assessment is made of the reasons why provisions to protect authors in their contractual rela-
\end{abstract}


tionships are inefficient when the contract turns international. Second, arguments are given to those proposals in favor of the establishment of an inalienable simple remuneration right to audiovisual authors administered by collective management organisations. The work closes with an assessment of the relevant role these organisations play on the protection of foreign audiovisual authors in Latin America.

Key words: audiovisual works, foreign author, territoriality principle, audiovisual contracts, simple remuneration right, collective management organisations.

\section{A (des)proteção do autor estrangeiro de obra audiovisual}

\section{Resumo}

O presente trabalho analisa as causas pelas quais o autor de uma obra audiovisual não recebe uma remuneração equitativa quando a sua obra é explorada em países estrangeiros. Tais razóes surgem da diferença entre as legislaçóes derivadas do princípio da territorialidade e as práticas contratuais dos produtores audiovisuais. Em seguida, se analisam as possíveis soluçóes a essa ausência de proteção partindo, em primeiro lugar, da explicação sobre as razóes as quais provocam que as normativas de proteção ao autor na contratação sejam ineficazes quando os contratos adquirem um caráter internacional. Em segundo lugar, se advoga pela adoção de um direito de simples remuneração pela exploração da obra audiovisual de caráter irrenunciável e administrado coletivamente. Por último, explica-se o importante papel que as sociedades de gestão coletiva possuem na proteção ao autor audiovisual estrangeiro na América Latina.

Palavras-chave: obra audiovisual, autor estrangeiro, princípio da territorialidade, contratos de produção audiovisual, direito de simples remuneração, sociedades de gestấo coletiva

\section{Introducción ${ }^{1}$}

Resulta generalmente aceptado que aunque los autores de obras audiovisuales tengan reconocidos derechos de exclusividad sobre sus trabajos, raramente obtienen una remuneración proporcional por su entera explotación. Y ello, a pesar de la existencia de un consenso internacional de que los autores merecen ser remunerados equita-

1 El presente trabajo está basado en un trabajo previo que forma parte del $E s-$ tudio sobre el marco jurídico audiovisual en América Latina publicado por el Comité de Desarrollo y Propiedad Intelectual (CDIP) de la OMPI y que pueden encontrarse en https:/www.wipo.int/ip-development/en/agenda/ work_undertaken.html. Se publica con la autorización de la OMPI. 
tivamente por la explotación de sus obras (Society of Audiovisual Artist, 2015; Xalabarder, 2018, p. 9). ${ }^{2}$ Este deficiente tratamiento también se observa en América Latina y, con algunas excepciones, en los ordenamientos que son objeto de análisis en el presente trabajo: Argentina, Brasil, Costa Rica, Ecuador, Perú y Uruguay. ${ }^{3}$

La situación resulta más injusta, si cabe, en aquellos supuestos en los que las obras se explotan en mercados diferentes al del Estado de origen de la obra de manera simultánea o sucesiva. Esta circunstancia no es, ni mucho menos, excepcional. En los últimos años, el mercado audiovisual se está transformando por la llegada de las tecnologías digitales y de los servicios en línea. Si bien las tradicionales ventanas de explotación y calendarios de apertura nacionales siguen vigentes, la disponibilidad inmediata de contenidos audiovisuales a nivel mundial a través de internet no para de crecer (Xalabarder, 2018, p. 10). Las plataformas de video a la carta (Netflix, Amazon o HBO, entre otras) están proliferando y, generalmente, ofrecen sus servicios a nivel internacional. En la actualidad, todo tipo de contenidos pueden ser accedidos gratuitamente, a cambio de publicidad, bajo suscripción o sistemas de pago por visión, lo que ha llevado a

Quiero dar las gracias a las siguientes personas, a las que tuve el gusto de entrevistar en el marco de este trabajo y cuyas opiniones han servido para su elaboración: Germán Gutiérrez (Argentores, Argentina), Eduardo de Freitas (AGADU, Uruguay), Ramiro Rodríguez (SENADI, Ecuador), Federico Duret (UNIARTE, Ecuador), Paula Siqueiros (GEDAR, Brasil), Ana Grettel Coto (Costa Rica), Martín Moscoso (Perú), Fernando Zapata (Colombia), María Mateo (SGAE, España), Leonardo de Terlizzi (CISAC). Cualquier comentario o inexactitud es responsabilidad exclusiva del autor.

2 Como se indica en el Executive Summary de la Society of Audiovisual Artist (2015), el éxito del sector audiovisual europeo no está derivando en una mayor remuneración de los directores y guionistas europeos. Los miembros de la asociación encargados del informe estiman que solo un 0,37\% de las ganancias del sector va a parar a sus miembros. Por su parte, R. Xalabarder (2018, p. 10), en su excelente informe para CISAC (Confederación Internacional de Sociedades de Autores y Compositores), sostiene que esta situación es similar en el mundo entero.

3 Un análisis del marco normativo nacional e internacional aplicable a la explotación de la obra audiovisual en estos países puede encontrarse en García León (2021). 
la doctrina a plantearse cuánto más pueden durar los modelos de explotación tradicionales. ${ }^{4}$

Si bien es cierto que las producciones de obras audiovisuales exigen grandes inversiones y conllevan elevados riesgos (Hugenholtz y Poort, 2020), la explotación de contenidos sin límites geográficos conlleva un incremento exponencial de los ingresos que estas plataformas pueden obtener de sus producciones. Lamentablemente, esto no se ve necesariamente reflejado en un aumento de la remuneración de los autores proporcional al incremento de los ingresos que estas plataformas generan. El problema no se limita exclusivamente a la explotación en medios digitales. Los autores tampoco son adecuadamente remunerados por la representación de sus obras en cines, o en canales de televisión por cable o radiodifusión o por el alquiler de sus obras. Generalmente, los autores reciben un pago único por la cesión de todos sus derechos y, en la mayoría de casos, no participan en los ingresos generados por la posterior explotación de la obra (Xalabarder, 2018, p. 10).

El objetivo del presente trabajo es, por un lado, analizar las causas de esta desprotección de los autores cuando la obra audiovisual es objeto de explotación a nivel internacional, y, por otro, explicar las medidas adoptadas o que se pueden adoptar para eliminar o reducir el problema.

A mi modo de ver, como se expone en el siguiente epígrafe, las principales causas son dos: las divergencias existentes entre las legislaciones nacionales de propiedad intelectual y las facilidades que encuentran las plataformas para eludir las normativas de protección de los autores en la contratación cuando el contrato adquiere un carácter internacional.

Las medidas implementadas en los ordenamientos objeto de análisis para favorecer la protección de los autores de obra audiovisual serán tratadas en el epígrafe 3. Como se explicará, las sociedades o entidades de gestión colectiva (en adelante, SGC) están jugando un papel importante en este sentido, aunque no están presentes en to-

4 La pregunta ahora es en qué momento estos servicios dominarán el mercado audiovisual en detrimento de los modelos de negocio de retransmisión audiovisual tradicionales. 
dos los Estados de América Latina. Además, una solución completa al problema solo puede conseguirse a partir de una actuación normativa armonizada a nivel internacional destinada a generalizar la adopción en las legislaciones nacionales de un derecho irrenunciable de simple remuneración por la reproducción y comunicación pública de las obras audiovisuales de gestión colectiva obligatoria.

Antes de empezar a explicar las causas, debe advertirse que el presente trabajo se centra en la figura del autor de obra audiovisual, aunque muchas de las conclusiones a las que se llegan podrían ser aplicables analógicamente a otros titulares de derechos como, por ejemplo, los intérpretes.

\section{Las divergencias entre legislaciones y la explotación internacional de la obra audiovisual}

Las legislaciones sobre propiedad intelectual presentan diferencias, por cuanto cada una de ellas responde a objetivos de política legislativa propios de cada país y a circunstancias socioeconómicas y tradiciones culturales especiales. Con carácter general, es habitual distinguir entre los ordenamientos del sistema de derecho continental (o droit d'auteur) y los de sistema anglosajón (o copyright).

Estas diferencias legislativas se acentúan todavía más en lo que se refiere a la regulación de la obra audiovisual. La razón de ello reside en la complejidad que reviste la producción y explotación de esta categoría de obras como consecuencia de una serie de factores:

a) Su producción exige la participación de una pluralidad de personas que llevan a cabo diversas contribuciones de carácter creativo, técnico, comercial o empresarial. El resultado es que una producción audiovisual da lugar a una pluralidad de objetos de protección (obra audiovisual, las interpretaciones, la grabación audiovisual) y titulares de derechos (autores, intérpretes y productores).

b) La producción de una obra audiovisual requiere de una fuerte inversión que lleva a cabo el productor y está sujeta a elevados riesgos, por cuanto puede ser difícil prever si la obra tendrá o no éxito comercial y, por lo tanto, si generará ingresos (Hugenholtz y Poort, 2020, p. 169).

c) Asu vez, la producción audiovisual y sus diferentes elementos 
(banda sonora, guiones, etc.) son susceptibles de ser explotados en diversas modalidades y, al contrario de lo que ocurre con otras categorías de obras, en una pluralidad de mercados.

Dependiendo de la ponderación que cada Estado le otorgue a los intereses de las diferentes personas involucradas en la producción y explotación de la obra audiovisual, la regulación varía, dando lugar a importantes diferencias en las legislaciones nacionales (Saiz García, 2002, p. 26). A efectos expositivos, estas diferencias pueden dividirse en dos grupos: las referidas a la autoría y titularidad originaria de la obra y las relativas al contenido de los derechos del autor de obra audiovisual, y cómo estos pueden resultar afectados por los contratos. ${ }^{5}$

Los convenios internacionales garantizan un cierto grado de armonización de dichas legislaciones y un ámbito de protección básico de los autores más allá de su país de origen. No obstante, no son útiles para superar los obstáculos que se derivan de estas divergencias legislativas para la explotación de las obras audiovisuales y la protección de los autores en el extranjero (Saiz García, 2002, pp. 111 y ss.). Ello es debido a la dificultad para superar el principio de

5 En relación con el objeto de protección, con base en el concepto amplio de "obra cinematográfica" acogida en el Convenio de Berna (artículo 2.1: "Las obras cinematográficas a las cuales se asimilan las obras expresadas por procedimiento análogo a la cinematografía"), todos los ordenamientos objeto de estudio garantizan la protección de todas las categorías de obras audiovisuales. También existe una regulación armonizada en lo que respecta al término de protección (70 años), aunque el sistema de cómputo de dicho plazo varía: en algunos casos, desde el fallecimiento del último autor (Costa Rica, Uruguay), en otros, desde la publicación de la obra (Brasil, Ecuador, Perú). Argentina es la excepción a la regla, por cuanto el plazo de protección alcanza los 50 años tras el fallecimiento del último autor. Tampoco se aprecian diferencias importantes que puedan afectar la explotación internacional de la obra audiovisual por lo que respecta al régimen de excepciones. Salvo Perú, ninguno de los países recoge la copia de la obra para uso privado (en Perú existe incluso la excepción para comunicación pública dentro de un ámbito privado). El Código Ingenios de Ecuador (en adelante, COESC) recoge, junto a una larga lista de excepciones, otra genérica de "usos justos" que, en cualquier caso, deben respetar la regla de los tres pasos. También cabe mencionar en la legislación de este país la existencia de licencias obligatorias (legales) que se pueden solicitar a la autoridad nacional sobre obras audiovisuales que no estén disponibles en el mercado nacional (en este sentido, ver García León, 2021). 
territorialidad que impregna la regulación de la materia y justifica la adopción de la norma de conflicto lex loci protectionis (ley del lugar de protección) para determinar la ley aplicable en supuestos de explotación internacional de las obras (Fawcett y Torremans, 2011).

\subsection{La autoría y titularidad originaria de la obra audiovisual}

Las regulaciones nacionales sobre la autoridad y titularidad originaria de la obra audiovisual pueden dividirse en dos grupos (González Gozalo, 2001, pp. 102-123). El primero, habitual de los sistemas de copyright, en los que todos los derechos de explotación se concentran en la persona física o jurídica que actúa como productor. Bajo la doctrina del work made for hire, dicha persona es considerada autor y titular originario. Es el sistema adoptado, por ejemplo, en Estados Unidos, Australia o China. De esta manera, se facilita enormemente la explotación de la obra, pues todos los derechos se concentran en una misma persona.

Un segundo grupo de países, correspondiente a los de tradición droit d'auteur, califica las obras audiovisuales como obras colectivas o en colaboración, y todas las personas que contribuyen creativamente a la obra son considerados coautores. Estas legislaciones contienen una lista de personas que pueden ser consideradas autores: generalmente, el director, el guionista y el compositor de la música creada especialmente para la producción audiovisual. No obstante, estas listas pueden incluir a otras personas, que varían de una legislación a otra. Dichas regulaciones vienen acompañadas de una presunción iuris tantum, según la cual estos autores le otorgan al productor la cesión en exclusiva de los derechos de explotación sobre la obra. Con ello se pretende facilitar la explotación de la obra, concentrando todos los derechos en una sola persona.

Las legislaciones de propiedad intelectual de América Latina, y en particular las de los países objeto del presente estudio, pertenecen al segundo grupo. En principio, esta circunstancia facilita la explotación de la obra en varios países de la región. No obstante, pueden aparecer dos tipos de problemas.

Por un lado, debido a que las listas de personas que pueden ser consideradas autores son taxativas, puede ocurrir que una persona que es reconocida como autor en un país no lo sea en otro. Así, por ejemplo, 
en Argentina, el compositor únicamente es considerado autor si se trata de una película de género musical. En este país y en Costa Rica, el productor es considerado coautor y, por lo tanto, recibe el mismo tratamiento que el autor de obra audiovisual. ${ }^{6}$ En cambio, en estos países no se reconoce esta condición al diseñador de los dibujos de una obra audiovisual animada. Es decir, esta persona es considerada autor, pero no de obra audiovisual, reconocimiento que sí recibe en las legislaciones de los otros países objeto de estudio. En Perú, Ecuador y Uruguay se considera autor de obra audiovisual al autor de la obra preexistente, cosa que no ocurre en el resto de ordenamientos. ${ }^{7}$

Por poner un ejemplo hipotético, un diseñador uruguayo de dibujos de una obra audiovisual animada es considerado autor audiovisual en su país y, por lo tanto, tiene un derecho de remuneración simple. No obstante, no recibirá esta calificación en Argentina, por lo que sus derechos no son de gestión colectiva obligatoria. A su vez, un productor argentino, en la medida en que no es reconocido como autor en Uruguay, no tiene derecho de remuneración simple por la explotación de sus obras en este país.

Por otro lado, también resulta problemática la relación de estas legislaciones con los ordenamientos del sistema copyright. Los problemas aparecen cuando autores de países latinoamericanos celebran contratos con productores estadounidenses o de otros países de sistemas copyright. Generalmente, dichos contratos, que suelen presentar un contenido estándar, establecen que la autoría y titularidad originaria de los derechos sobre las obras le corresponden al productor. Asimismo, estos contratos pueden incluir una cláusula de elección de ley del país de domicilio del productor para garantizar la aplicación de la normativa contractual de ese país y, en particular, la doctrina del work made for hire.

En estos supuestos cabe plantearse si las personas que tienen la condición de autores de acuerdo con la legislación de su país de ori-

6 En ambos casos, se interpreta que únicamente puede ser considerado coautor el productor persona física. En este sentido, véanse las tablas de legislación de Argentina y de Costa Rica en García León (2021).

7 Se puede encontrar una comparación de estas legislaciones en García León (2021). 
gen (del sistema droit d'auteur) pierden esa condición por el hecho de haber renunciado a la autoría de acuerdo con una ley extranjera (de sistema copyright) que lo permite.

La doctrina se decanta por ofrecer una respuesta negativa a esta cuestión (Desbois et al., 1976, p. 152; Goldstein y Hugenholtz, 2010, p. 130). Las partes del contrato de producción audiovisual tienen libertad contractual para regular los aspectos contractuales de la relación, pero no los aspectos de propiedad intelectual. Es decir, el contrato no puede determinar quién puede ser considerado autor o titular originario de la obra. Se trata de una cuestión que debe determinar la ley que rige el derecho de propiedad intelectual, es decir, la lex loci protectionis. Así lo establece expresamente el artículo 14 bis, 2 a) del Convenio de Berna (CB), al que nos referiremos más adelante (González Gozalo, 2013, p. 1180; Rycketson y Ginsburg, 2005, párr. 7.32.). ${ }^{8}$ Esto implica que cuando la obra es explotada en varios países, será la normativa de cada uno de ellos la que determine quién es considerado autor o titular originario de la obra audiovisual. Lo mismo ocurre con la determinación de las creaciones que son susceptibles de protección o del contenido del derecho de exclusividad: todas son cuestiones a determinar por la lex loci protectionis, no por la lex contractus.

Por lo tanto, con independencia de lo que diga el contrato, la persona que ha contribuido a la creación de obra será considerada autor en todos aquellos países en los que la obra se explotada, si es que recibe dicha consideración en la ley de ese país.

\subsection{El contenido de los derechos sobre la obra audiovisual y su afectación por el contrato}

Con carácter general, todas las legislaciones de países de América Latina, y en particular las analizadas para el presente estudio, reco-

8 Como explica A. González Gozalo (2013), en la medida en que constituía una cuestión conflictiva, en la Conferencia de Estocolmo se decidió evitar una regulación material de la cuestión y optar por esta norma de conflicto que otorga plena libertad a los Estados miembros para atribuirle la titularidad de la obra audiovisual a quien estimen oportuno. 
nocen al autor o titular originario de obra audiovisual todos los derechos patrimoniales, incluido el de puesta a disposición en internet. ${ }^{9}$ No obstante, a partir de aquí se aprecian algunas diferencias que es importante señalar.

En primer lugar, en Argentina, la gestión de los derechos de exclusividad sobre la obra audiovisual es de gestión colectiva obligatoria (García León, 2021, p. 48). Las SGC correspondientes (Argentores para los guionistas, Directores Argentinos Cinematográficos [DAC] para los directores y la Sociedad Argentina de Autores y Compositores de Música [SADAIC] para compositores de bandas sonoras) ${ }^{10}$ tienen el monopolio legal sobre la explotación de los derechos. Gracias a ello, los autores salen fortalecidos, por cuanto no se ven obligados a negociar en condiciones de inferioridad con los productores y tienen asegurada una adecuada remuneración. Del mismo modo, los usuarios también deben abonar una remuneración por la explotación de las obras a estas entidades a partir de tarifas establecidas por el Gobierno.

El carácter irrenunciable de estos derechos y su gestión colectiva obligatoria son dos aspectos importantes de esta regulación. Al contrario que en Argentina, en Brasil se ha introducido la gestión colectiva de los derechos de exclusividad, pero se considera que los autores pueden renunciar por contrato a todos sus derechos. ${ }^{11} \mathrm{De}$ confirmarse esta interpretación, la efectividad de la medida disminuiría, por cuanto las SGC, para solicitar una remuneración por la explotación de la obra, se verían obligadas a probar que el autor se reservó dichos derechos en el contrato con el productor. En tal caso, la posición del autor no mejoraría, pues los productores podrían seguir obligándolo a renunciar a todos sus derechos y la gestión colectiva perdería su efectividad. Del mismo modo, la medida no benefi-

9 Y ello aunque Brasil todavía no haya ratificado el Tratado OMPI de Derechos de autor (TODA).

10 Desde 2004, SADAIC dejó de percibir el derecho de comunicación pública por la música incluida en obras audiovisuales, por una decisión judicial (Sociedad Argentina de Autores y Compositores c/Andesmar S.A., CSJN, S. 129. XXXVII, 23 de marzo de 2004).

11 Véase la Tabla sobre la legislación brasileña incorporada al estudio de García León (2021). 
ciaría a los autores de obras cuya explotación se rige por contratos ya vigentes en los que el productor se quedó con todos los derechos. La gestión de los derechos sobre estas obras no podría ser cedida a una SGC, salvo que se modificara el contrato.

A pesar de los beneficios de la legislación argentina, esta presenta una limitación: la obligación de gestión colectiva está referida únicamente a la explotación de los derechos en territorio argentino. Es decir, los autores están protegidos en lo que respecta a la reproducción, distribución y comunicación pública de la obra audiovisual en Argentina. Pero para la cesión de los derechos sobre la obra para otros países rige la libertad contractual, por lo que los productores pueden imponer sus condiciones y solicitar, por ejemplo, la cesión de la totalidad de los derechos.

A su vez, estas divergencias legislativas resultan perjudiciales para los productores, por cuanto deben tener en cuenta que, aunque el autor les haya cedido todos los derechos, la explotación de la obra en Argentina debe ser autorizada por las SGC correspondientes, circunstancia que puede conllevar conflictos entre productores y usuarios, dado que estos últimos pueden entender que una vez pagado al productor, ya no deben realizar más pagos para explotar la obra.

En segundo lugar, además de los derechos de exclusividad, algunas legislaciones nacionales le otorgan al autor un derecho de remuneración simple por la comunicación pública de la obra de carácter irrenunciable y de gestión colectiva obligatoria. Es el caso de Uruguay, ${ }^{12}$ que introdujo este derecho para guionistas y directores en diciembre de 2019, aunque todavía no se ha empezado a cobrar. ${ }^{13}$ En Ecuador también se recoge este derecho de remuneración simple, pero únicamente por el alquiler de la obra y por su exhibición en lugares públicos con precio de entrada. ${ }^{14}$ La ley peruana reconoce un derecho de simple remuneración por la transferencia de la interpre-

12 También se establece en otros países de la región, como Colombia y Chile.

13 Dado lo reciente de la ley, por el momento AGADU (Asociación General de Autores de Uruguay) solo administra este derecho en relación con los autores de obra musical.

14 Artículo 154, incisos 5 y 6 del COESC. De acuerdo con García León (2021), en Ecuador, al igual que otros países como Perú, Costa Rica o Brasil, sí se establece este derecho para productores y artistas audiovisuales. 
tación a un medio distinto, pero no parece que esté implementada (García León, 2021, p. 42).

El carácter irrenunciable y de gestión obligatoria de este derecho implica que la cesión de derechos hecha por el autor al productor no alcanza, en ningún caso, al derecho de remuneración simple. Al igual que en el caso anterior, si bien es un derecho que no está obligado a pagar el productor, se pueden producir situaciones conflictivas en las relaciones con los usuarios de la obra: el contrato celebrado con el productor por la explotación de la obra no les exime de pagar el derecho de remuneración en aquellos países que lo establezcan.

También se debe tener presente que el derecho de simple remuneración presenta una limitación: se calcula, exclusivamente, a partir de la explotación de las obras en el territorio del Estado cuyo ordenamiento lo establece, no en relación con la explotación de la obra a nivel mundial.

En tercer lugar, el alcance de las presunciones de cesión de derechos al productor varía de un ordenamiento a otro. Así, en Uruguay, Costa Rica o Perú, la cesión se refiere a la totalidad de los derechos patrimoniales sobre la obra cinematográfica, mientras que en Ecuador la cesión está referida a algunos de esos derechos (en particular, los de reproducción, distribución y comunicación pública), por lo que la explotación de la obra en cualquier otra modalidad (por ejemplo, transformación) exigiría la autorización de los autores. Esta situación se presenta también en Brasil, de cuya legislación se interpreta que la cesión tiene carácter no exclusivo y se concede para la explotación de obras audiovisuales en su medio principal de explotación (circunstancia que conlleva la necesidad de estar al caso concreto). ${ }^{15}$ Debe recordarse que estas presunciones solo entran en juego en defecto de contrato, circunstancia que hace más necesaria, si cabe, la utilización de contratos modelo unificados por parte de los productores para establecer un régimen uniforme de la explotación internacional de la obra.

En cuarto lugar, todos los países objeto de estudio reconocen, en mayor o menor medida, derechos morales a todas las categorías de autores de obra audiovisual y establecen su carácter inalienable,

15 Artículo 81 de la ley brasileña, citada en García León (2021). 
irrenunciable e intransferible. La excepción sería Costa Rica, que solo le reconoce estos derechos al director. ${ }^{16} \mathrm{La}$ legitimación para hacer valer estos derechos varía de un ordenamiento a otro: en algunos países, su ejercicio se le atribuye en exclusividad al director (Brasil) o conjuntamente con el productor (Brasil, Perú y Uruguay, salvo disposición en contrario). ${ }^{17}$ Esta circunstancia puede suponer un obstáculo insalvable en el supuesto caso de que un productor y los autores que no son directores quisieran hacer valer judicialmente los derechos morales sobre la obra audiovisual de manera unitaria -es decir, no en relación con cada una de sus aportaciones- en una pluralidad de Estados. Podrían estar legitimados en unos países, pero no en otros.

\subsection{Explotación internacional de las obras audiovisuales y la lex loci protectionis}

Las diferencias legislativas anteriormente expuestas no generan problemas en aquellos supuestos (excepcionales) en los que la obra se explota exclusivamente en el país de origen. Los conflictos aparecen cuando la obra es objeto de exportación a otros países. En estos casos, como es conocido, la protección de los autores se articula a partir de cuatro principios previstos en los tratados internacionales:

a) Estándar mínimo de protección (artículo 5.1 y artículo 19 del $\mathrm{CB}$, artículo 1.1 del Acuerdo sobre los aspectos de propiedad intelectual relacionados con el comercio, ADPIC), aunque, como se ha visto, la armonización de mínimos que establecen los tratados internacionales no es suficiente para evitar los problemas que derivan de las divergencias legislativas.

b) Principio de territorialidad (artículo 5.2 del CB), según el cual las leyes de propiedad intelectual de un país determinado se aplican únicamente a la protección y explotación de la obra intelectual en el territorio de dicho país.

16 El productor tiene la obligación de citar en los créditos a todos los autores de la obra audiovisual, lo que, aunque defectuoso, constituye un reconocimiento del derecho de paternidad de estos.

17 La comparación la obtengo de García León (2021). 
c) Principio de trato nacional (artículo 5.1 del CB y artículo 3.1 del ADPIC), que obliga a los Estados contratantes de los convenios internacionales a ofrecer a los autores de obras originarias de otros Estados contratantes el mismo trato que a sus nacionales.

d) Principio de independencia (artículo 5.2 del CB), que garantiza que la protección de una obra no se hace depender de la protección que esta pueda tener en su país de origen.

Todos estos principios conllevan que la norma de conflicto aplicable en supuestos de explotación internacional de las obras sea la lex loci protectionis o la ley del lugar para el que se reclama la protección. Así viene establecida en el artículo 5.2 del CB ("[...] la extensión de la protección así como los medios procesales acordados al autor para la defensa de sus derechos se regirán exclusivamente por la legislación del país en que se reclama la protección”) y en los sistemas nacionales y supranacionales de derecho internacional privado. ${ }^{18}$ Esta norma de conflicto conlleva, además, que cuando la obra se explota en una pluralidad de Estados, la ley de cada uno de ellos resulta aplicable para la explotación de la obra en su territorio (Carrascosa González, 2004). ${ }^{19}$

Algunos Estados han ofrecido soluciones conflictuales diferentes para regular cuestiones particulares de esta explotación. Así, por ejemplo, en Bélgica, la determinación del titular originario del derecho de propiedad intelectual se rige por la ley más estrechamente vinculada, ${ }^{20}$ solución que evita la aplicación de una pluralidad de

18 En la Unión Europea, artículo 8.1 Reglamento 864/2007 (R. Roma II).

19 La posibilidad que ofrecen algunos sistemas de derecho internacional privado de presentar una demanda en defensa de los derechos de autor en un Estado diferente a aquel donde se explota la obra o se produce la información debe llevar a sostener que el artículo 5.2 seńala como aplicable la ley del Estado para cuyo territorio se reclama la protección, y no la ley del Estado en el que se reclama la protección.

20 Artículo 93 del Código de Derecho internacional privado belga: "Les droits de propriété intellectuelle sont régis par le droit de l'Etat pour le territoire duquel la protection de la propriété est demandée. Toutefois, la détermination du titulaire originaire d'un droit de propriété industrielle est régie par le droit de l'Etat avec lequel l'activité intellectuelle présente les liens les plus étroits. Lorsque l'activité a lieu dans le cadre de relations contractuelles, il est présumé, sauf preuve contraire, que cet Etat est celui dont le droit est appli- 
leyes cuando la demanda se presenta ante sus tribunales. Del mismo modo, en más de una ocasión, la jurisprudencia francesa ${ }^{21}$ y la estadounidense ${ }^{22}$ se han decantado por la aplicación de la ley de origen de la obra para la determinación de esta misma cuestión. Asimismo, el artículo 67 de la ley griega de derechos de autor establece la aplicación de la ley del Estado de primera publicación de la obra para todas las cuestiones, excepto la protección de la obra. ${ }^{23}$

Estas soluciones favorecen la explotación internacional de las obras en la medida en que la persona que es considerada autor en el Estado de origen no pierde esta condición cuando la obra es explotada en otros países. No obstante, se pueden generar problemas de coherencia normativa derivados del hecho de que cuestiones íntimamente relacionadas con la titularidad de un derecho y su protección estén reguladas por leyes diferentes. Del mismo modo, estas normas de conflicto generan inseguridad jurídica e incrementan los costes de información de los usuarios, por cuanto la autoría y la titularidad de las obras explotadas en un mercado vendrían establecidas por la ley de origen de cada una de ellas (Fawcett y Torremans, 2011, pp. 345 y ss.).

Estas razones conllevan que la solución generalmente aceptada a nivel internacional sea la lex loci protectionis. Ello, a pesar de los problemas que genera. Es más, como se ha indicado anteriormente, el artículo 14.2 (a) del CB rechaza cualquier otra solución que no sea esta a la hora de determinar la ley aplicable a la titularidad originaria de la obra audiovisual: "La determinación de los titulares del derecho de autor sobre la obra cinematográfica queda reservada a la legislación del país en que la protección se reclame" (González Gozalo, 2013, p. 1196). ${ }^{24}$

cable à ces relations".

21 Sentencia de la Corte de Casación, 7 de abril de 1998, SAAB Scania c/Soc. Diesel Tecnic, RIDA, N 177, p. 255.

22 Itar-Tass News Agency vs. Russian Kurier Inc., 153 F.3d 82.

23 El texto puede consultarse en https://www.wipo.int/edocs/lexdocs/laws/en/ gr/gr001en.pdf.

24 En este sentido, como explica A. González Gozalo (2013), los Estados de la Unión de Berna pueden adoptar la lex originis en sus legislaciones nacionales para determinar cualquier tipo de obra, excepto las audiovisuales. En este último caso, prevalece el artículo 14.2. (a) del CB. 
En definitiva, las divergencias legislativas y la aplicación de la lex loci protectionis deviene en una desprotección de los autores cuando la obra es objeto de explotación en un país diferente al de su origen. Piénsese, por ejemplo, en un guionista uruguayo de una película que tiene un gran éxito comercial en toda América Latina. Aunque sea reconocido como autor en todos los países objeto de estudio, obtendrá una remuneración simple por la explotación de la obra en su país de origen, pero no por la explotación en países como Perú o Ecuador, donde no se reconoce este mismo derecho.

También puede producirse el supuesto inverso, es decir, que un autor esté protegido o reciba un trato más beneficioso en el extranjero que en el Estado de origen de la obra. Esta circunstancia es consecuencia del principio de independencia: aunque un director peruano no obtenga una remuneración proporcional por la explotación de la obra en su país, tendrá derecho a recibir una compensación por la explotación en Uruguay o en Argentina. Del mismo modo, una persona que otorga la autoría de la obra al productor en un contrato regulado por la ley de California (Estados Unidos) seguirá siendo considerado autor (y, por lo tanto, estará protegido) en, por ejemplo, Perú, Brasil o Argentina, es decir, en aquellos Estados en los que la autoría es intransferible. En estos casos, el principio de trato nacional viene al auxilio de la regla lex loci protectionis.

Ahora bien, el reconocimiento legal de protección del autor extranjero en estos supuestos no garantiza, por sí solo, su efectividad práctica. Para que el autor reciba una cantidad dineraria en concepto de remuneración proporcional por la explotación de su obra, es preciso habilitar mecanismos de cooperación que pasan necesariamente por la intervención de las SGC. A estos mecanismos nos referiremos en el último apartado del estudio.

\section{La ineficiencia de la normativa de protección del autor en los contratos internacionales de producción audiovisual}

Las divergencias legislativas derivadas del principio de territorialidad no solo afectan a los autores, sino también a los productores, porque la producción audiovisual puede involucrar autores residentes en diferentes Estados y porque, generalmente, el objetivo plasmado 
en el contrato será explotar la obra resultante en una pluralidad de Estados. Para superar los obstáculos derivados de las divergencias legislativas, los productores recurren a contratos modelo, en los que se unifican los términos de la producción y explotación de la obra con independencia de los mercados en los que se lleve a cabo (Xalabarder, 2018, p. 20).

En principio, el recurso a contratos modelo por parte de los productores no es criticable. De hecho, debe ser bienvenido, por cuanto hasta cierto punto unifica el régimen jurídico aplicable a la explotación internacional de la obra, favoreciendo así la aparición de un mercado audiovisual regional del que pueden resultar beneficiados muchos colectivos (los propios autores, las cadenas de televisión nacionales, los consumidores finales, todas aquellas personas que trabajan para productoras audiovisuales, etc.) y que puede enriquecer culturalmente a la región (García León, 2021, p. 51).

Pero estos contratos devienen problemáticos cuando en ellos se introducen cláusulas que perjudican los intereses de los autores y no garantizan una remuneración proporcional a la explotación real de la obra. Tal es el caso, por ejemplo, cuando a cambio de una remuneración a tanto alzado, el autor le cede al productor los derechos de explotación sobre la obra para cualquier modalidad conocida o por conocer, para el mundo entero y por el espacio de tiempo que dure la protección. Son las llamadas buy-out clauses. Con ellas, como hemos dicho, el productor unifica contractualmente el régimen de protección de la obra para facilitar su explotación con una pluralidad de titulares de derechos, en diferentes mercados y a lo largo del tiempo. No obstante, es una situación injusta para los autores: si la obra se convierte en un éxito, los autores no resultan beneficiados. Esta circunstancia es especialmente dañina cuando, como ocurre actualmente, los medios digitales ofrecen la posibilidad de explotar internacionalmente la obra, incrementando las posibilidades de éxito con escasos costes ańadidos.

La negociación colectiva mediante sindicatos o entidades de gestión puede ayudar a aliviar estos problemas. Pero, para ello, se necesitan sindicatos poderosos de representación de los autores, cosa que solo sucede en un puñado de países del Common Law como Estados Unidos (Xalabarder, 2018, p. 13). Las SGC pueden jugar un papel importante en este sentido, ya sea negociando con los productores 
en representación de los autores o apoyando a los autores en dicha negociación a partir de la promoción de cláusulas modelo que garanticen una adecuada protección de sus intereses. Así, por ejemplo, se podrían promocionar cláusulas por las cuales los autores se reserven ciertos derechos de exclusividad cuya gestión puede posteriormente ser cedida a SGC (las cláusulas carve-out). No obstante, no parece que en la región existan sindicatos, asociaciones de autor o SGC con un poder negociador suficiente como para imponer estas cláusulas a los productores.

La excepción es Argentina. En este caso, en la medida en que los derechos de exclusividad de los autores audiovisuales son de gestión colectiva obligatoria, los autores resultan adecuadamente protegidos en sus relaciones contractuales con las productoras. No obstante, como se ha advertido anteriormente, incluso en este caso se presentan limitaciones cuando el contrato prevé la explotación de la obra en el extranjero.

Una segunda vía para evitar que el autor resulte perjudicado consiste en el establecimiento de normas relativas a las cesiones de derechos destinadas a proteger al autor como parte débil de estas transacciones. Estas normas son habituales en los ordenamientos pertenecientes al sistema de droit d'auteur, pero no en los del sistema de copyright, en los que se considera que las cesiones de derechos se rigen por la normativa general de la contratación (Von Lewinsky, 2008, párrs. 3.70-3.72).

Todos los ordenamientos objeto del presente estudio pertenecen al sistema de droit d'auteur, aunque sus normativas presentan ciertas diferencias. Así, existen leyes que obligan a que el contrato mencione expresamente cada una de las modalidades de explotación transferidas $^{25}$ (reservando para el autor aquellas que no lo son) o que prohíben la transmisión de los derechos sobre obras futuras ${ }^{26}$ o sobre modalidades de explotación no existentes en el momento de celebrar

25 Artículo 89 del Decreto Legislativo 822 de Perú; artículos 167 y 168 del COESC de Ecuador.

26 Artículo 167 del COESC. El artículo 51 de la Ley 9610/1998 de Brasil determina que "[l]a cesión de derechos de autor sobre obras futuras abarcará un máximo de cinco ańos [...]". 
el contrato. ${ }^{27}$ En el caso de la Ley uruguaya, el artículo 32 indica que si el productor no explota la obra, el autor o sus causahabientes pueden requerirle que lo haga, y si pasado un ańo este no cumple, el autor recupera sus derechos. ${ }^{28}$ Otras leyes establecen que la duración de la cesión de derechos está limitada en el tiempo: 10 años en la ley brasileña $^{29}$ o 15 tras la muerte del autor en la uruguaya. ${ }^{30}$

El problema de estas normas es que la protección que dispensan al autor se desmorona desde el momento en que el contrato de producción audiovisual adquiere carácter internacional. Efectivamente, incluso si estas normas poseen un carácter imperativo (es decir, que no son derogables por contrato), la introducción de una cláusula de elección de ley extranjera conllevará la inaplicación de dichas normas. En su lugar, se aplicarán, si es que existen, las normas de protección del autor establecidas en la ley elegida. Si esta pertenece al sistema de copyright, dicha protección sencillamente desaparece.

Para garantizar que la normativa de protección del autor no pueda ser burlada mediante la elección de una ley extranjera, los Estados pueden optar por dotar a esa normativa de un carácter internacionalmente imperativo. Es decir, debe establecer expresamente que las normas de protección de los autores protegen un interés fundamental para el ordenamiento jurídico en cuestión y, por lo tanto, resultan aplicables si las partes han elegido una ley extranjera. ${ }^{31}$

Un ejemplo de lo que decimos lo encontramos en el ya citado artículo 32 de la Ley 9739 de derechos de autor de Uruguay, que declara el carácter de orden público de la disposición. ${ }^{32}$ No obstante,

\section{Artículo 167. II del COESC.}

28 Artículo 32.

29 Artículo 81.1.

30 Artículo 33.

31 Se puede encontrar un concepto de norma internacional en el artículo 9.1 del Reglamento 593/2008 sobre la ley aplicable a las obligaciones contractuales (Roma I): "Una ley de policía es una disposición cuya observancia un país considera esencial para la salvaguardia de sus intereses públicos, tales como su organización política, social o económica, hasta el punto de exigir su aplicación a toda situación comprendida dentro de su ámbito de aplicación, cualquiera que fuese la ley aplicable al contrato [...]". También se puede consultar el artículo 2543 Código Civil y Comercial de Argentina.

32 "Esta disposición es de orden público, y el adquirente sólo podrá eludirla por 
la disposición no establece su ámbito espacial de aplicación, es decir, a qué contratos internacionales se aplica. Si bien ese ámbito puede extraerse implícitamente de su finalidad y contenido, resulta preferible establecerlo expresamente para evitar la inseguridad jurídica que se deriva de la dificultad de determinar la aplicación de la norma en casos concretos (Hernández Rodríguez, 2002, pp. 101 y ss.). ${ }^{33}$

Así, por ejemplo, el artículo 32.a de la ley alemana de propiedad intelectual regula el derecho del autor para solicitar judicialmente la revisión de la remuneración a tanto alzado prevista en el contrato cuando no resulte ajustada a la explotación real de la obra. El artículo 32.b establece la aplicación internacionalmente imperativa de esta disposición si, en defecto de elección de ley, el derecho aplicable al contrato fuera el alemán o, en caso contrario, cuando el contrato estuviera referido a actos de explotación a llevar a cabo en el territorio de Alemania.

En cualquier caso, la atribución de un carácter internacionalmente imperativo a las normas de protección del autor no garantiza por sí sola su eficiencia. En primer lugar, porque obliga al autor a reclamar sus derechos ante un órgano jurisdiccional, lo cual implica importantes costes que, por lo general, los autores por sí solos no se pueden permitir. Para ello, deberían contar con la ayuda de las SGC o de asociaciones profesionales.

En segundo lugar, porque ese órgano jurisdiccional será, generalmente, extranjero. Efectivamente, además de la cláusula de elección de ley, estos contratos suelen incluir un acuerdo de elección de tribunales que habitualmente atribuye la jurisdicción a los del Estado de domicilio del productor. En tal caso, debe recordarse que las normas de protección del autor son consideradas leyes de policía por el Estado que las promulga, pero pueden no serlo para el Estado

causa de fuerza mayor o caso fortuito que no le sea imputable".

33 Este podría ser el caso, por ejemplo, del artículo 47 de la Ley de propiedad intelectual espańola (LPI), en el que se regula la acción de revisión por regulación no equitativa. En atención a la finalidad de la norma (proteger los intereses de los autores) y del hecho de que el artículo 55 establezca el carácter irrenunciable de esta facultad, se puede inferir que constituye una ley de policía que resulta de aplicación imperativa incluso cuando la ley aplicable al contrato fuera extranjera. 
ante cuyos tribunales hay que presentar la demanda. Como es lógico pensar, si los tribunales designados son los de un Estado del sistema de copyright, difícilmente dichos tribunales harán prevalecer las normas internacionalmente imperativas de un tercer Estado sobre la regulación prevista en la ley designada por el contrato.

Lo mismo ocurrirá, en principio, en aquellos supuestos en los que el contrato modelo incluya una cláusula arbitral: por lo general, los árbitros harán primar la autonomía de la voluntad de las partes expresada en el contrato. Únicamente en aquellos supuestos en los que se corra el riesgo de adoptar un laudo que resulte anulable o irreconocible en el Estado donde debe de ser ejecutado, los árbitros podrían tomar en consideración lo que dicen las normas internacionalmente imperativas de ese Estado. ${ }^{34}$

La única manera de garantizar el cumplimiento de esta normativa es estableciendo una norma de jurisdicción inderogable mediante contrato por la que se le atribuya al autor la facultad de presentar la demanda ante los tribunales del país de origen de la obra. Hasta donde conocemos, dicha norma no existe en ningún sistema de derecho internacional privado y no parece una solución acertada por cuanto podría ser visto por los productores como una sobreprotección de los autores nacionales y podría desincentivar la realización de proyectos audiovisuales en los países que las establezcan.

Una última razón por la que no se considera adecuado el recurso a normas internacionalmente imperativas reside en que su proliferación dificultaría la explotación internacional de las obras. Al no ser derogables mediante contrato, el productor audiovisual que quisiera explotar la obra a nivel internacional no podría unificar el régimen de explotación mediante contrato, por cuanto debería tomar en consideración las leyes de policía existentes en cada uno de los Estados en los que se va a explotar la obra. El aumento en costes de información y la inseguridad jurídica que ello conlleva podría

34 Y ello porque, de llegar a considerarse que las normas de protección de autor forman parte del contenido del orden público de un ordenamiento, el laudo arbitral podría resultar anulable en atención a la causa de anulación relativa a la contrariedad con el orden público; además, podría no ser ejecutable en un país extranjero por incurrir en la causa de denegación de contrariedad con el orden público prevista en el artículo VII del Convenio de Nueva York de 1958. 
desincentivar a los productores a explotar sus producciones en un mercado regional. Se perderían, así, los beneficios que la creación de ese mercado conlleva.

\section{Medidas que favorecen la protección del autor extranjero de obra audiovisual}

Analizadas las razones que explican la desprotección del autor cuando la obra es explotada a nivel internacional, en este último epígrafe se pretende analizar las medidas que se están implementando a nivel nacional o que se pueden adoptar para garantizarles a los autores una remuneración equitativa. Dichas medidas consisten en la cooperación entre SGC de diferentes países y en el refrendo legislativo del derecho de simple remuneración por explotación de la obra audiovisual.

\subsection{El papel de las sociedades de gestión colectiva}

Con carácter general, las entidades o sociedades de gestión colectiva juegan un papel fundamental para garantizar la protección de los autores (Xalabarder, 2020, p. 498). En particular, resultan esenciales para asegurarle al autor una remuneración por la explotación de la obra audiovisual en el extranjero.

En América Latina, estas instituciones tienen un fuerte arraigo en el sector musical, no así en el audiovisual. Con la excepción de Argentina, donde Argentores (guionistas) y DAC (directores) están consolidadas desde hace tiempo, las entidades de gestión de los autores de obra audiovisual son de aparición reciente. Es el caso de AGADU en Uruguay; UNIARTE en Ecuador; y GEDAR (guionistas), MUSIMAGEM (compositores), DBCA (directores) y ABCA (cine de animación) en Brasil. Solo en dos de los países objeto de análisis para el presente trabajo (Perú y Costa Rica) no existen todavía SGC para los autores de obras audiovisuales, aunque no se descarta que puedan establecerse en el futuro.

La experiencia demuestra que la aparición de estas SGC depende, en buena medida, de la evolución del mercado audiovisual nacional y de la generación de una masa crítica de personas que deciden asociarse para defender sus derechos. Las particularidades de cada 
mercado nacional también conllevan que dichas SGC puedan representar exclusivamente a autores o que incluyan a otros titulares de derechos. Es el caso, por ejemplo, de Ecuador, donde UNIARTE representa a autores e intérpretes audiovisuales, y podría ser el caso de otros países. ${ }^{35}$

La creación de estas SGC no solo está promovida por esa masa crítica conformada por los autores audiovisuales nacionales, sino que también resulta de interés para las SGC extranjeras, pues de esta manera se facilita la protección de los intereses de sus representados cuando la obra audiovisual es explotada en el extranjero. Por ello no es de extrañar que sean las SGC extranjeras las que impulsen la creación de estas entidades en otros Estados. Así ha ocurrido en el pasado en relación con la gestión de otros derechos con EGEDA o SGAE.

La existencia de intereses comunes también explica la aparición de asociaciones supranacionales, como la Federación de Sociedades de Autores Audiovisuales Latinoamericanos (FESAAL), ${ }^{36}$ que impulsa la creación de estas SGC en aquellos países donde todavía no existen. La formación de estos organismos internacionales debe ser bienvenida, pues favorece la cooperación entre SGC, beneficiando, en última instancia, a los autores.

La colaboración entre SGC se articula de manera muy sencilla a través de acuerdos de representación recíproca. Hasta donde hemos podido conocer, dichos acuerdos presentan una estructura similar, por cuanto están basados en un contrato modelo de CISAC, que si bien actualmente ya no está auspiciado por esta entidad, en la práctica se sigue utilizando en la región.

La creación de una SGC en un Estado beneficia a los autores de ese país incluso si la legislación nacional no les otorga una protección adecuada. Ello es así porque la cooperación entre SGC permitirá que

35 Un ejemplo de cómo el mercado afecta la constitución o no de SGC lo ofrece Perú. La regla general por mucho tiempo ha sido que los directores creaban sus propias productoras para producir sus películas. Por lo tanto, ambas titularidades de derechos recaían en las mismas personas, lo que hacía innecesario crear dos SGC. Por un tiempo se intentó que EGEDA (productores) aglutinara también a autores audiovisuales, aunque finalmente quedó sin efecto.

36 Información disponible en https://www.fesaal.org. 
estos autores reciban una remuneración por la explotación de la obra en países extranjeros. Así, por ejemplo, los guionistas representados por GEDAR todavía no reciben una remuneración por la explotación de sus obras en Brasil. No obstante, gracias al acuerdo de representación recíproca con DAC, sí obtienen una remuneración por la explotación de sus obras en Argentina. Del mismo modo, los autores ecuatorianos representados por UNIARTE pueden beneficiarse del derecho de simple remuneración previsto en la legislación uruguaya gracias al acuerdo entre esta sociedad y AGADU.

Estos ejemplos permiten constatar el respeto que los Estados y las SGC otorgan al principio de trato nacional, en la medida en que estas reparten regalías a autores nacionales de países extranjeros que no conceden a los autores de la nacionalidad de la SGC, y la eficiencia del principio de independencia contemplado en el Convenio de Berna, pues, gracias a la cooperación entre estas entidades, un autor audiovisual puede resultar más protegido en un país extranjero que en su propio país.

Los acuerdos de representación recíproca permiten identificar a los autores representados por cada SGC, pero la manera de calcular la tasa de uso de las obras de cada uno de ellos en el territorio de cada Estado le corresponde determinarla a cada SGC.

Esta tarea resulta complicada en relación con las modalidades tradicionales de explotación (televisión, exposición en cines), por cuanto se debe confiar en las declaraciones ofrecidas por los operadores, aunque no existan muchos mecanismos para comprobar la veracidad de los números ofrecidos. No obstante, la digitalización de las obras audiovisuales y la generalización de su explotación por medios electrónicos facilita este cálculo y su control por las SGC y las autoridades competentes (Schötz, 2021). En última instancia, esta circunstancia favorece a los autores porque recibirán remuneraciones más ajustadas a la explotación real de sus obras y con mayor celeridad.

Esta mayor facilidad para calcular el uso de las obras en el entorno digital, unido al incremento en la explotación multiterritorial de las obras audiovisuales, son dos argumentos de peso para que las SGC profundicen en sus esquemas de colaboración, habilitando sistemas que permitan centralizar la gestión colectiva de los derechos a nivel regional. En este sentido, resulta aconsejable estudiar la posibilidad 
de implementar un sistema similar al existente en el sector musical, como es Latinautor (De Freitas, 2020), mediante el cual: a) a modo de ventanilla única, los usuarios pudieran negociar de manera unitaria la explotación de las obras para varios países, si así lo desearan; y b) se pudiera calcular, de manera eficiente y haciendo uso de sistemas informáticos sofisticados, el uso que se hace de la obra por cada usuario en cada Estado y calcular la regalía que le corresponde regionalmente a cada autor. El sistema, como puede observarse, está basado en la centralización de la negociación, pero las licencias a otorgar pueden seguir siendo nacionales y emitidas por cada SGC. La idea no es adoptar un sistema de licencias multiterritoriales como el existente en la Unión Europea. ${ }^{37}$

La adopción de este tipo de sistema de gestión centralizada favorecería la aparición de un mercado audiovisual regional, pues aquellos usuarios que lo desearan podrían negociar en un solo sitio las licencias que necesitan para la explotación de la obra en varios mercados nacionales. A su vez, se beneficiaría a los autores por cuanto las SGC podrían utilizar sistemas informáticos, a los que muchas de ellas difícilmente podrían tener acceso de manera individual, para calcular de manera eficiente cuál ha sido el uso de sus obras y la remuneración proporcional que le correspondería a cada autor por cada país.

\subsection{Los beneficios del derecho de simple remuneración}

Los beneficios que la cooperación entre SGC conlleva no pueden esconder que muchos Estados siguen sin garantizar una remuneración equitativa a los autores audiovisuales nacionales o extranjeros por la explotación de la obra audiovisual en sus territorios.

Para ello, es necesario que estos Estados acometan reformas legislativas, las cuales deben ser impulsadas por los propios autores audiovisuales, las SGC y sus asociaciones. Según se ha explicado en el apartado anterior, no creemos que esas reformas legislativas deban tener como objetivo la reforma de la normativa sobre protección del autor en sus relaciones contractuales. Estamos de acuerdo con

37 En relación con la adaptación del sistema europeo a la realidad de América Latina puede consultarse Olarte Collazos (2020). 
la doctrina que ha estudiado la cuestión en que la mejor manera de garantizarles a los autores una remuneración proporcional a la explotación real de su obra pasa por la introducción de un derecho de simple remuneración en las leyes nacionales de propiedad intelectual (Mateo Orobia, 2015; Xalabarder, 2018).

Son muchos los Estados que han optado por la adopción de este derecho. El último ejemplo es Uruguay, que, como ya se ha mencionado, lo introdujo en 2019. De los ordenamientos objeto del presente trabajo, es el único en el que se regula con carácter general. También existe en otras legislaciones de la región, como la colombiana ${ }^{38}$, la mexicana ${ }^{39}$ y la chilena, ${ }^{40}$ o de Europa, como la espańola. ${ }^{41}$ Asimismo, en otros países objeto del presente trabajo, como Perú o Ecuador, está previsto para artistas e intérpretes.

No puede descartarse que, en los próximos años, la maduración de los mercados audiovisuales nacionales, unido al impulso de los autores nacionales de obra audiovisual, sus asociaciones de representación y las SGC, conlleven la introducción de este derecho en otras legislaciones de la región.

Con carácter general, este derecho tiene las siguientes características: se trata de un derecho de simple remuneración (no de exclusividad) que el autor de obra audiovisual disfruta durante el plazo de protección de la obra audiovisual por cualquier acto de explotación de esta; es un derecho de carácter irrenunciable e intransferible y de gestión colectiva obligatoria; las personas obligadas a subsanarlo son los usuarios de las obras.

La introducción de este derecho tiene varias ventajas puestas de manifiesto, en parte, por Xalabarder (2020, p. 494):

a) El autor disfruta de este derecho con independencia del contenido del contrato con el productor (es irrenunciable) e independientemente de la remuneración a tanto alzado o proporcional que haya podido acordar con él. En este sentido, la posición negocial de inferioridad del autor deja de ser un problema.

38 Artículo 98 de la Ley 23 de 1982.

39 Artículo 26 bis Ley Federal del Derecho de Autor.

40 Ley 20959 de 2016.

41 Artículo 90 de la LPI. 
b) La gestión por las SGC facilita enormemente las cosas a los autores, por cuanto son estas entidades las que se encargan de su gestión. Además, el derecho asegura un flujo constante y directo de remuneración para los autores a lo largo de la vida de la obra, siempre y cuando se generen ingresos por su explotación.

c) Se trata de un derecho que disfrutan los autores de obras audiovisuales creadas con posterioridad a su introducción legislativa y también los de obras ya existentes. No resulta necesario modificar los contratos ya existentes que rigen la explotación de estas últimas obras para que sus autores disfruten del derecho.

En principio, el refrendo legal de este derecho de remuneración simple también tiene la ventaja de que no obliga a modificar los contratos de producción audiovisual ya existentes ni los futuros. Es decir, su introducción reglamentaria no obliga a los productores a modificar sus contratos ni al autor a pactar la reserva de derechos. La remuneración de los autores queda garantizada sin necesidad de revisar ni renegociar los contratos de producción.

Ahora bien, en la medida en que el derecho debe ser pagado por los usuarios de las obras, es lógico pensar que se produzcan cambios en las licencias de explotación celebradas entre estos y los productores. Es igualmente lógico entender que estos intentarán negociar una rebaja en el precio de la licencia justificada en la necesidad que tienen de hacer frente a esta remuneración simple. ${ }^{42}$ Las modificaciones que pudieran introducirse en las licencias de explotación podrían, en última instancia, repercutir en los autores, los cuales podría ver reducidas las cantidades que los productores se obligan a pagarles a tanto alzado antes de la producción de la obra en la medida en que van a participar en los ingresos que se deriven de su explotación comercial.

La introducción de este derecho de manera dispar de unos orde-

42 No resulta convincente la explicación de Xalabarder, según la cual la introducción del derecho de simple remuneración también beneficia a los licenciatarios. La remuneración de los autores no supone un coste ańadido para el licenciatario, sino una remuneración parcial por la licencia de derechos exclusivos obtenido del productor. Como indica Xalabarder (2020), "si se deducen o no las cantidades de la licencia de derechos exclusivos depende de la elasticidad del mercado, así como del acuerdo entre el productor y el operador" (p. 499). 
namientos u otros puede generar obstáculos en la explotación internacional de las obras audiovisuales y, por consiguiente, dificultar la aparición de un mercado audiovisual regional, con los beneficios que ello conllevaría.

Este último problema podría salvarse si el derecho de simple remuneración se introdujera mediante una norma de carácter internacional (como ha ocurrido en el Tratado de Beijing para los intérpretes audiovisuales ${ }^{43}$ ) o regional (como se intenta en la Unión Europea): ${ }^{44}$ como el derecho vendría establecido por todos los países de la región, el régimen jurídico de la explotación de la obra no variaría de un Estado a otro. ${ }^{45}$ Pero para crear esa norma supranacional hace falta el apoyo de la comunidad de autores audiovisuales ${ }^{46}$ y voluntad política. En este sentido, llama la atención que la Decisión CAN 351 no haya sufrido cambios desde su adopción y que los países miembros de la Comunidad Andina hayan desarrollado esta normativa básica de maneras divergentes: mientras Colombia ha reconocido este derecho, Ecuador lo ha hecho de manera muy reducida y nada se establece en las legislaciones nacionales de Perú y Bolivia. También es significativo que a pesar de la proliferación de acuerdos bilaterales celebrados por países de América Latina, en ninguno de ellos se haya abordado la cuestión. Todo ello parece indicar que esa norma internacional o regional que garantice una regulación armonizada de un derecho de simple remuneración resulta, por ahora, de difícil alcance.

43 Artículo 12.3.

44 En Europa, el artículo 18 de la Directiva 2019/790 obliga a los Estados a garantizar que "cuando los autores y los artistas intérpretes o ejecutantes concedan licencias o cedan sus derechos exclusivos para la explotación de sus obras $\mathrm{u}$ otras prestaciones, tengan derecho a recibir una remuneración adecuada y proporcionada”. No obstante, el apartado 2 otorga libertad a los Estados miembros para alcanzar este objetivo. Sobre el particular, ver Saiz García (2020, pp. 367-411).

45 Parte 2: Estudio sobre el marco jurídico audiovisual en el entorno audiovisual.

46 En este sentido, debe citarse el Manifiesto de México auspiciado por Writes \& Directors WorldWide. Disponible en http://www.writersanddirectorsworldwide.org/mexico-manifesto/. 


\section{Conclusiones}

Las divergencias en las regulaciones nacionales de derechos de autor provocan que el autor de obra audiovisual no resulte adecuadamente remunerado por la explotación de la obra en países diferentes al de origen.

Este problema se está acrecentando como consecuencia de la llegada de las plataformas digitales, por cuanto el ámbito de explotación de las obras es regional o, incluso, mundial. Es lógico que estas plataformas utilicen contratos estándar para unificar el régimen jurídico de la producción y explotación de las obras audiovisuales y, así, eludir los problemas que se derivan de esas divergencias legislativas. No obstante, dichos contratos pueden incluir cláusulas que acrecienten la deficiente protección de los autores cuando la obra es objeto de explotación internacional.

Resulta difícil encontrar soluciones regulatorias a este problema que satisfagan todos los intereses en presencia. Por un lado, se constata que las normativas nacionales sobre protección de los autores en la contratación son ineficaces cuando la producción y explotación de la obra audiovisual adquiere carácter internacional.

Por otro, la introducción de un derecho de simple remuneración en las legislaciones nacionales puede beneficiar a los autores, pero puede obligar a los productores a replantear las relaciones con los licenciatarios y dificultar la explotación internacional de las obras al acrecentarse las divergencias legislativas. Esto supondría un obstáculo a la aparición de un mercado regional audiovisual. Una posible solución a este problema podría venir de la mano de la adopción de una normativa armonizada a nivel regional o internacional, la cual, en el momento actual, no parece muy probable.

Por último, debe señalarse la importante labor que juegan las SGC en este escenario de divergencias legislativas e intereses contrapuestos, para asegurar, hasta donde les resulte posible, que los autores tengan acceso a una remuneración equitativa por la explotación de sus obras audiovisuales a nivel internacional. 


\section{Bibliografía}

Carrascosa González, J. (2004). Conflicts of Laws in a Centenary Convention: Berne Convention 9th September 1886 for the Protection of Literary and Artistic Works. En Mansel, H. P., Pfeiffer, T., Kronke, H., Kohler, C. y Hausmann, R., Festschrift für Erik Jayme (pp. 105-120). Sellier European Law Publishers.

De Freitas, E. (2020). Latinautor. Los licenciamientos regionales. El rol de las entidades de gestión colectiva manteniendo su jurisdicción en el territorial nacional. En Díez Alfonso, A. (Dir.), Cuadernos jurídicos: Instituto de Derecho de Autor $15^{\circ}$ aniversario (pp. 223-227), Instituto Autor.

Desbois, H., Françon, A. y Kéréver, A. (1976). Les conventions internationals du droit d'auteur et des droits voisins. Dalloz.

Fawcett, J. y Torremans, J. (2011). Intellectual Property and Private International Law. Oxford University Press.

García León, M (2021). Part 2: The Legal Framework of the Audiovisual Sector in the Digital Environment. En Organización Mundial de la Propiedad Intelectual, Estudio sobre el marco jurídico audiovisual en América Latina. https:// www.wipo.int/ip-development/en/agenda/work_undertaken.html.

Goldstein, P. y Hugenholtz, P. B. (2010). International Copyright: Principles, Law and Practice, Oxford University Press.

González Gozalo, A. (2001). La propiedad intelectual de la obra audiovisual. Comares. González Gozalo, A. (2013). Arts. 14 y 14 bis. En Bercovitz Rodríguez-Cano, R. (Coord.), Comentarios al Convenio de Berna (pp. 1137-1213). Tecnos.

Hernández Rodríguez, A (2002). Los contratos de edición en Derecho internacional privado español. Comares.

Hugenholtz, P. B. y Poort, J. (2020). Film Financing in the Digital Single Market: Challenges to Territoriality. International Review of Intellectual Property and Competition Law, 51, 167-186.

López-Tarruella Martínez, A. (2013). Art. 5. En Bercovitz Rodríguez-Cano, R. (Coord.), Comentarios al Convenio de Berna (pp. 393-453). Tecnos.

Mateo Orobia, M. (2015). Derecho de remuneración de autor para la explotación en linea de obras audiovisuales y el sistema español como la mejor alternativa. Comares.

Olarte Collazos, J. (2020). Licencias multiterritoriales en la gestión colectiva del derecho de autor y los derechos conexos: Perspectiva desde la Unión Europea y la Comunidad Andina de las Naciones. Instituto Autor.

Rycketson, S. y Ginsburg, J. (2005). International Copyright and Neighbouring Rights: The Berne Convention and Beyond. Oxford University Press.

Society of Audiovisual Artist. (2015). SAA White Paper: Audiovisual Authors' Rights and Remuneration in Europe. https:/www.saa-authors.eu/en/publications/55-saa-white-paper-2nd-edition.

Saiz García, C. (2002). Obras audiovisuales y derechos de autor. Thomson Aranzadi.

Saiz García, C. (2020). El principio de remuneración adecuada y proporcionada en la Directiva 2019/790/UE. En Saiz García, C. y Evangelio Llorca, R. 
(Dirs), Propiedad intelectual y mercado único digital (pp. 367-411). Tirant lo Blanch.

Schötz, G. (2021). Part. 5. The Identification and Use of Metadata in Audiovisual Works. En Organización Mundial de la Propiedad Intelectual, Estudio sobre el marco jurídico audiovisual en América Latina. https://www.wipo.int/ip-development/en/agenda/work_undertaken.html.

Von Lewinsky, S. (2008). International Copyright and Policy, Oxford University Press.

Xalabarder, R. (2018). International legal study on implementing an unwaivable right of audiovisual authors to obtain equitable remuneration for the exploitation of their works. CISAC. https://es.cisac.org/Universidad-CISAC/Biblioteca/Estudios-y-guias/Estudio-de-remuneracion-audiovisual.

Xalabarder, R. (2020). La remuneración equitativa de los autores audiovisuales mediante un derecho de remuneración irrenunciable de gestión colectiva. En Saiz García, C. y Evangelio Llorca, R. (Dirs.), Propiedad intelectual y mercado único digital (pp. 475-510). Tirant lo Blanch. 
